\title{
AN UNDOCUMENTED RARE BRANCHING PATTERN OF EXTERNAL CAROTID ARTERY
}

\author{
Sonu ${ }^{* 1}$, Sunita Kalra ${ }^{2}$.
}

Department of Anatomy, University College of Medical Sciences and Guru Teg Bahadur Hospital, Delhi, India.

\section{ABSTRACT}

The external carotid arterial system supplies the areas of head and neck region. The knowledge of possible anatomical variations occurring in branching pattern of external carotid artery is crucial especially in the surgeries of head, neck and face; as well as for interpretation of radiological investigations like angiograms. During routine dissection of head and region for undergraduate students we discovered common trunk for lingual, facial and ascending pharyngeal arteries. Also, the occipital artery is arising just before the common trunk from the external carotid artery.

KEY WORDS: External carotid artery, branches, common trunk, occipital artery.

Corresponding Author: Dr. Sonu, Senior Resident, Department of Anatomy, University College of Medical Sciences and Guru Teg Bahadur Hospital, Dilshad Garden, Delhi-110095

Phone: 9560580484 E-Mail: supreetkaur20@gmail.com

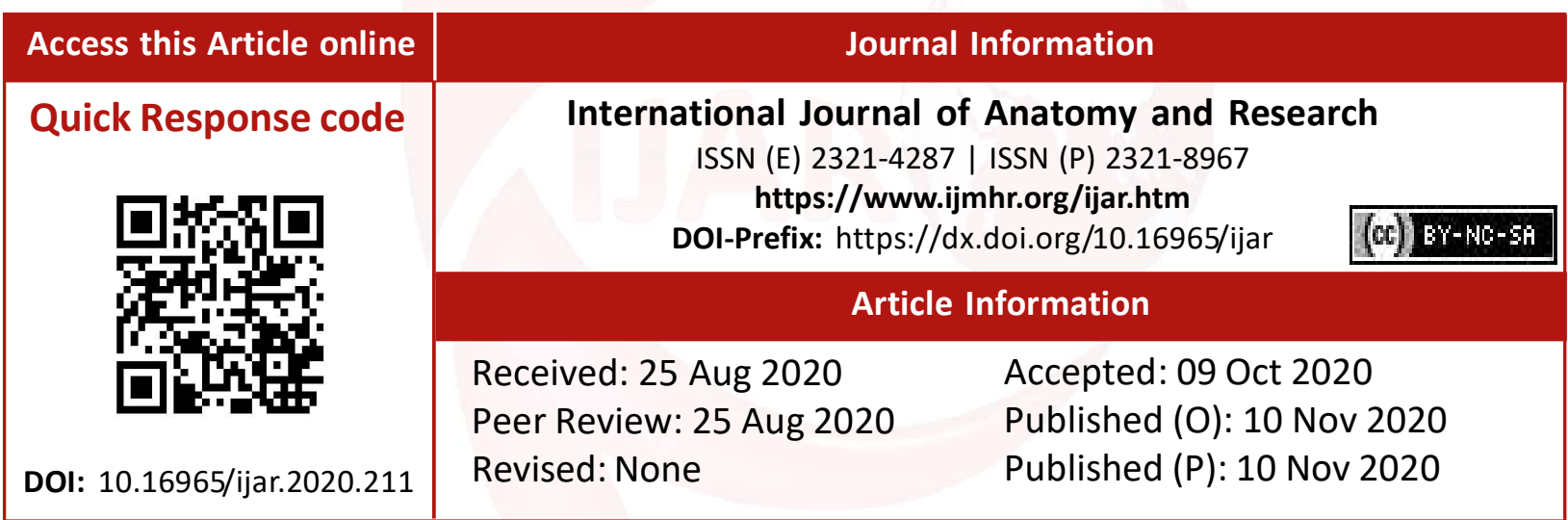

\section{INTRODUCTION}

Common carotid arteries are the major source of blood to the head and neck region including brain. These divide into its terminal branches namely internal and external carotid artery on either side of neck at the level of $4^{\text {th }}$ cervical vertebrae.

The external carotid artery travels upwards on both side of the neck and divides into the ascending pharyngeal, superior thyroid, lingual, facial, occipital and posterior auricular arteries, and then enters the parotid gland where it divides into its terminal branches, the superficial temporal and maxillary arteries [1]. External carotid artery supplies almost all of the structures present in the head and neck region. It has numerous anastomoses with the internal carotid artery as well as vertebrobasilar system thus ensuring blood supply in case of disturbed cerebral blood flow [2]. So, it is imperative to know its branching pattern as well any deviations from the usual in order to plan for interventional procedures in the head and neck region.

\section{CASE REPORT}

The study was conducted on a 60 years old male cadaver used for routine dissection of teaching undergraduate medical students. During routine dissection of neck region in the department of anatomy in a medical college, we observed one unusual common trunk emerging from the anterior aspect of the left external carotid artery. This common trunk was giving origin to lingual, facial and ascending pharyngeal arteries. The hypoglossal nerve was observed to be crossing anterior to the common trunk near its origin. Also, the occipital artery was emerging from external carotid 
artery immediately after it gave superior thyroid branch. This anomalous branching pattern of external carotid artery has not been reported in the literature.

\section{RESULTS AND DISCUSSION}

During routine dissection of side of neck for undergraduate students, following uncommon branching pattern of external carotid artery on the left side were observed by authors (Figure 1a \& 1b):

1) Lingual, facial and ascending pharyngeal arteries arising from one common trunk which was emerging from left external carotid artery

2) Occipital artery arising just after superior thyroid artery

Standard textbooks of anatomy describe external carotid artery is one of the terminal branches of common carotid artery usuallygiven at the upper border of thyroid cartilage which is corresponding to $4^{\text {th }}$ cervical vertebral level. It is positioned antero-medial to the internal carotid artery at its origin in the carotid triangle and then ascends towards the parotid gland and finally terminates into maxillary and superficial temporal arteries at the level of neck of mandible. The independent branches namely, superior thyroid, lingual, facial, ascending pharyngeal, occipital and posterior auricular in the neck emerge from external carotid artery [1].

In the present study authors found common trunk for lingual, facial and ascending pharyngeal arteries arising from left external carotid artery, in contradiction to a study by Shintani et al [3] which has reported thyrolingual trunk in $3.50 \%$ cases of his study.

Lappas et al [4] observed lingo-facial trunk in $14 \%$ cases of his study which is again dissimilar from our study. We could not comment upon percentage as our findings as we report a single undocumented case observed during routine dissection for teaching undergraduate medical students. Similarly, Anil A et al [5] observed lingo-facial trunk in 10 to $20 \%$ of cases similar to Yildrin et al [6] who noted it

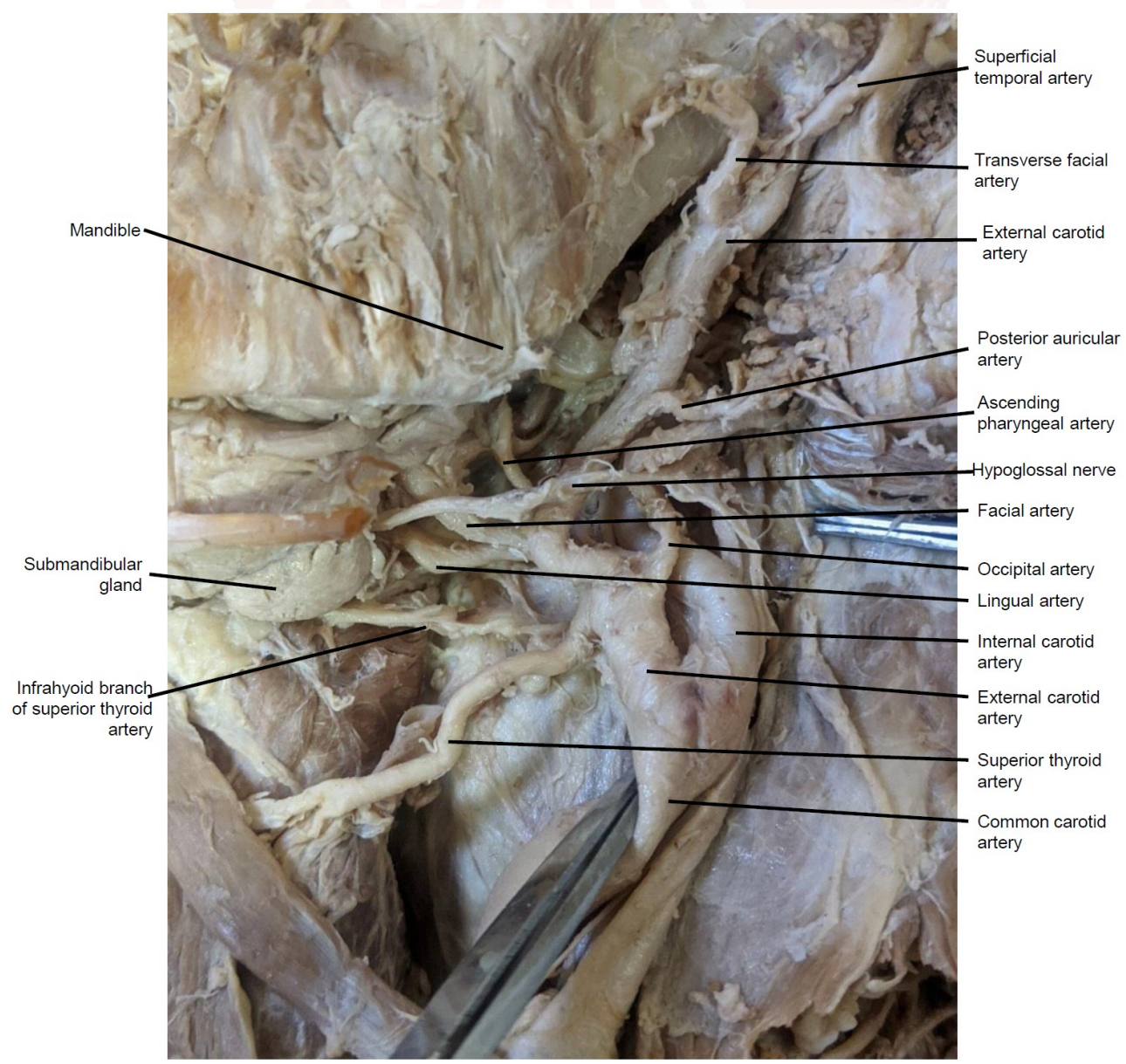

Fig. 1(a): Dissection of neck region on left side demonstrating branching pattern of external carotid artery; Lingual, facial and ascending pharyngeal arteries arising from one common trunk which was emerging from left external carotid artery; Occipital artery arising just after superior thyroid artery . 


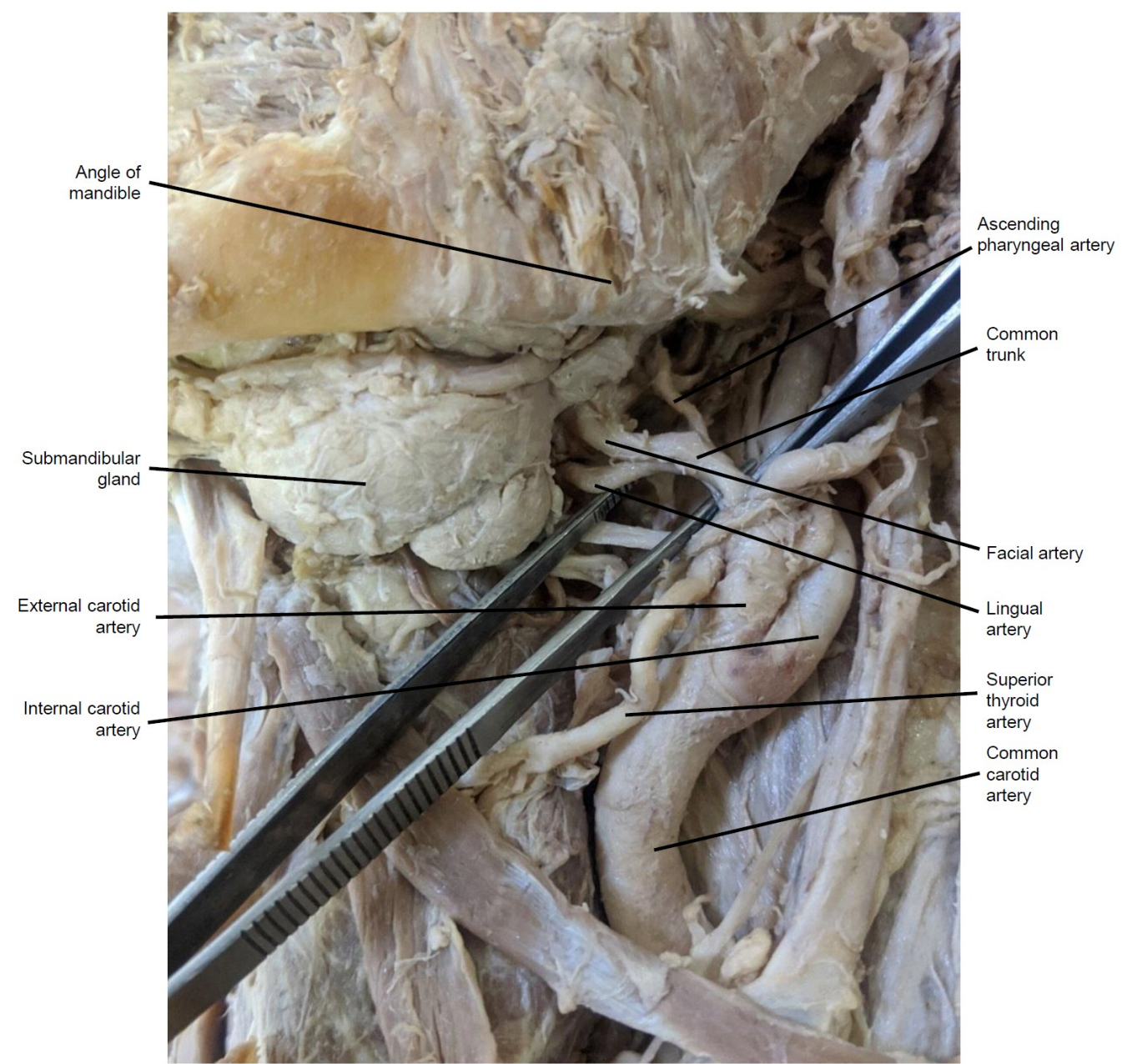

Fig. 1(b): Dissection of neck region on left side demonstrating branching pattern of external carotid artery (after retraction of hypoglossal nerve); Lingual, facial and ascending pharyngeal arteries arising from one common trunk which was emerging from left external carotid artery; Occipital artery arising just after superior thyroid artery.

in $15 \%$ of his study cases. Vishnu Gupta and Rakesh Agarwal [7] also found it in $13.3 \%$ of cases.

In another study by Sanjeev I $k$ et al [8] reported ascending pharyngeal artery to be arising from external carotid artery as separate branch in $75.6 \%$ of cases and in rest of the cases it was sharing common trunk with the occipital artery. In contradiction to this, the finding in the present report demonstrated a common trunk with lingual and facial arteries. He also reported occipital artery sharing common trunk with the posterior auricular artery in $2.70 \%$ cases. Whereas, authors of the present study observed separate occipital artery arising from posterior-lateral aspect of external carotid artery just before the thyrolingual facial trunk.

Embryological basis: Development of external carotid artery is a tangled process of angiogenesis and remodelling which involves annexation and regression of vessels. The development of hyostapedial artery which connects the neural crest arterial system to the ventral pharyngeal arterial system is crucial affair in the development of external carotid artery. Signals involved in annexation and regression are not always synchronized which results in various anatomical variation [9]. This explains the undocumented branching pattern of external carotid artery as being reported in the current study.

To the best of our knowledge and literature search the anomalous branching pattern of external carotid artery in the present study has not been reported yet.

\section{CONCLUSION}

The present study reported that Lingual, facial and ascending pharyngeal arteries arising from one common trunk from left external carotid artery. Also, Occipital artery 
was emerging just after superior thyroid artery. Presence of such variable pattern of branching of external carotid artery may cause inadvertent injury during head and neck surgeries. Also, they can cause confusion in interpretation of radiological investigations including angiograms.

Facial artery Musculo-mucosal (FAMM) flap [10] was introduced recently for reconstruction purposes. But its use is limited due to invariable course of facial artery. Hence, the exact knowledge of course as well as unusual branching pattern of facial artery as observed in the present report is obligatory for FAMM flap and its successful utilization.

\section{Conflicts of Interests: None}

\section{REFERENCES}

[1]. Standring S. Gray's Anatomy. The anatomical basis of clinical practice .39th Ed. Edinburg. Elsevier Churchill Livingstone. 2005; 31: p.543-544.

[2]. Osborn AG. Diagnostic cerebral angiography. 2nd ed. Philadelphia: Lippincott Williams and Wilkens, 1999; 31-55.

[3]. Shintani S, Terakado N, Alcalde RE, Tamizawa K, Narayas Ueyema $Y$ et al. An anatomical study of the arteries for intra-arterial chemotherapy of Head and Neck cancer. International Journal of Clinical Oncology. 1999; 4:327-330.

https://doi.org/10.1007/s101470050079
[4]. Lappas DA, Kamberos SP, Gisakis JG, Takis CH, Lykaki $G$. Anatomic study of the variations in the origin of the branches of the external carotid artery. Beta Medical Arts 2002:81.

[5]. Anil A, Turgut Hb, Peker T, Pelin C, Variations of the branches of the external carotid artery. Gazi Med J. 2000;11(2): 81-83.

[6]. Yildrin, M, Tanyeli, E, Solyluoglu, A. I: \& Tuna, Y. Truncus linguofacialis siklig. Morfoloji Der. 2001;9(1): 33-4.

[7]. Vishnu Gupta, Rakesh Agarwal. "Anomalous Branching Pattern of the External Carotid Artery in Cadavers". Int J Sci Stud. 2014;2(1):28-31.

[8]. Sanjeev I K, Anita H, Ashwini M, Mahesh U, Rairam $\mathrm{G} B$. Branching pattern of external carotid artery in human cadavers. Journal of Clinical and Diagnostic Research [serial online] 2010 October [cited: 2010 October 15]; 4:3128-3133.

[9]. Larsen W. Human Embryology. 2nd ed. New York: Churchill Livingstone, 1998: 191-195.

[10]. Pribaz J, Stephens W, Crespo L, Gifford G. A new intraoral flap: facial artery musculomucosal (FAMM) flap. Plast Reconstr Surg 1992; 90(3): 421-429.https://doi.org/10.1097/00006534199209000-00009 PMid:1513887

How to cite this article:

Sonu, Sunita Kalra. AN UNDOCUMENTED RARE BRANCHING

PATTERN OF EXTERNAL CAROTID ARTERY. Int J Anat Res 2020;8(4.1):7767-7770. DOI: 10.16965/ijar.2020.211 